\title{
Evaluation of regional fracture properties for groundwater development using hydrolithostructural domain approach in variably fractured hard rocks of Purulia district, West Bengal, India
}

\author{
TAPAs Acharya ${ }^{1, *}$, RAJesh Prasad ${ }^{1}$ and S Chakrabart ${ }^{2}$ \\ ${ }^{1}$ Department of Geology, Hooghly Mohsin College, University of Burdwan Chinsurah 712 101, India. \\ ${ }^{2}$ Department of Applied Geology \& Environmental Systems Management, Presidency University, 86/1 \\ College Street, Kolkata 700073 India. \\ ${ }^{*}$ Corresponding author.e-mail: tacharya3@yahoo.com
}

\begin{abstract}
Estimation of geohydrologic properties of fractured aquifers in hard crystalline and/or metamorphosed country rocks is a challenge due to the complex nature of secondary porosity that is caused by differential fracturing. Hydrologic potentiality of such aquifers may be assessed if the geological controls governing the spatial distribution of these fracture systems are computed using a software-based model. As an exemplar, the Precambrian metamorphics exposed in and around the Balarampur town of Purulia district, West Bengal (India) were studied to find out the spatial pattern and consistency of such fracture systems. Surfer and Statistica softwares were used to characterize these rock masses in terms of hydrological, structural and lithological domains. The technique is based on the use of hydraulically significant fracture properties to generate representative modal and coefficient of variance $(C \nu)$ of fracture datasets of each domain. The $C \nu$ is interpreted to obtain the spatial variability of hydraulically significant fracture properties that, in turn, define and identify the corresponding hydrolithostructural domains. The groundwater flow estimated from such a technique is verified with the routine hydrological studies to validate the procedure. It is suggested that the hydrolithostructural domain approach is a useful alternative for evaluation of fracture properties and aquifer potentiality, and development of a regional groundwater model thereof.
\end{abstract}

\section{Introduction}

Evaluation of geohydrological properties of hard crystalline and/or metamorphosed rocks is a difficult task owing to the heterogeneity, variability and complexity of structural features (such as fractures) that are associated with these masses. The nature and pattern of these fracture distributions principally govern the zones of groundwater enrichment and determine their flow path through the fractured conduits. Fracture networks have the potentiality to significantly influence local and regional scale fluid movement. Fracture induced permeability depends on density of fractures, size of apertures and connectivities (Singhal and Gupta 1999). It is assumed that closely spaced fractures with higher frequency represent better possibility of fluid flow (Mabee and Hardcastle 1997). Several researchers (Braathen 1999; Henriksen and Braathen 2006; Boutt et al. 2010; Acharya et al. 2012) have recognized enhanced permeability amongst hydraulically significant flowing-fractures

Keywords. Fractured rocks; geostatistics; heterogeneity; hydraulic properties; metamorphic rocks. 
and high fracture frequencies. Theoretical and experimental studies show the influence of size and distribution of apertures of fractures on the permeability status and fluid flow dynamics (Tsang and Witherspoon 1981; Oda 1985; Brown 1987; Bertels et al. 2001; Auradou et al. 2005; Matsuki et al. 2006; Pan et al. 2010). The term 'hydrostructure' refers to the nature of secondary porosity within a particular bedrock unit. A group of bedrocks exhibiting similar hydrostructural features is termed as a 'hydrostructural unit' (Abbey and Allen 2000). Characterizing the regional scale permeability in areas of heterogeneous and complex disposition of fractures is a problem because of multiple orientations and cross-cutting relationships amongst fracture networks (Mabee and Kopera 2007). The possible solution lies in recognizing the hydrostructural features, like fractures and faults, which help groundwater movement. The approach utilises the concept of dividing the aquifers into structural domains based on regionalscale structural data (Ohlmacher 1999; Martin and Tannant 2004; Surrette and Allen 2008). Each domain is characterized by a unique set of hydraulic properties different from the other domain in geometry, orientation and distribution of structural elements and associated fabric (Mackie 2002; Surrette et al. 2008). At the megascopic scale, faults and shear zones that typically featured in metamorphic terrains dominate the fracture morphology and hydrological characteristics, and cast a major influence on the hydrostructural domain (Lapcevic et al. 1999; Wang et al. 2002; White and Burbey 2007). Interestingly, Manda et al. (2007) have indicated overlapping hydraulic interrelationships/conductivities between adjacent hydrostructural domains and suggested that fracture characteristics derived on the basis of only the hydrostructural approach do not always give a significant clue to the exact nature of a domain. They observed the need of other criteria to further classify these to narrower 'conductivity units'. With this view, it was considered to incorporate adjusted hydraulically significant properties of fracture sets, such as fracture frequency, aperture, etc., for estimation of the more constrained measures of hydraulic conductivities in variably fractured hard rock domains.

The present study area is situated in and around Balarampur town of Purulia district, West Bengal, India, extending between latitudes $23^{\circ} 01^{\prime} 52^{\prime \prime}$ and $23^{\circ} 06^{\prime} 55^{\prime \prime} \mathrm{N}$ and longitudes $86^{\circ} 12^{\prime} 00^{\prime \prime}$ and $86^{\circ} 20^{\prime} 24^{\prime \prime} \mathrm{E}$ (figure 1). The area is underlain by variably fractured/jointed metamorphic rock masses and the geologically significant South Purulia Shear Zone (SPSZ) trending in E-W direction.

Regional scale groundwater development is important in these water starved semi-arid stretches that represent the westernmost province of West Bengal where groundwater occurring in fractured, low-yielding bedrock aquifers is the sole source of potable water for domestic and agricultural uses (Mallik et al. 1983; Nag 1999). Several investigations carried out in the past to study the lineaments and subsurface bedrock-fractures in and around Balarampur town have shown three 'domains' of fractured terrain: (a) the domain occurring north of the SPSZ (D1), (b) the domain within the SPSZ (D2) and (c) the region south of the SPSZ (D3) (Acharya et al. 2012; Acharya and Mallik 2012). Furthermore, SPSZ (D2) was suggested as a more hydraulically significant region with higher fracture frequencies (Mallik et al. 1983; Nag 1999; Acharya et al. 2012; Acharya and Mallik 2012) compared to D1 and D3.

The objective of this paper is to assess the hydrological potentiality of a highly metamorphosed Precambrian terrain based on hydrolithostructural domain approach on fracture systems.

\section{General geological set-up}

Geologically, the study area is located at the junction of Chhotanagpur Granite Gneissic Complex (CGGC) and the Iron Ore Group (IOG) of rocks of Proterozoic age (Baidya 1992; Geological Quadrangle Map 73I 1948; Gupta and Basu 2000) (figure 1). On the north, CGGC is a part of the Chhotanagpur craton consisting different types of granite gneisses, such as quartz-biotite, granite gneiss and porphyroblastic granite gneiss. The IOG exposed on the south belongs to the Singhbhum orogenic belt and comprises chiefly of mica schist and phyllite. The metasediments of IOG are interlayered with basic bodies, locally described as epidiorite sills (Geological quadrangle map 73I 1948). NW-SE foliations are well developed both in the CGGC and the metasedimentaries of IOG (Geological quadrangle map 73I 1948). The rocks have no primary porosity and flow of water is restricted to fracture zones. The dip of foliations is high $\left(>57^{\circ}\right)$ and northerly directed. Presence of more than one generation minor fold is observed that bears imprints of polyphase deformation. Geometry of the first generation fold is not visible owing to absence of competent exposures. A prominent shear zone trends almost E-W through the south of Balarampur town. This shear zone is termed as the 'South Purulia Shear Zone' (SPSZ) that possesses the features of a brittle-ductile deformational regime (Bhattacharya 1989; Dasgupta 2004) (marked in figure 1). There are evidences of shear forces that acted along some E-W trending near-vertical weak planes during the third tectonic period (Geological quadrangle map 73I 1948). A thrust has 

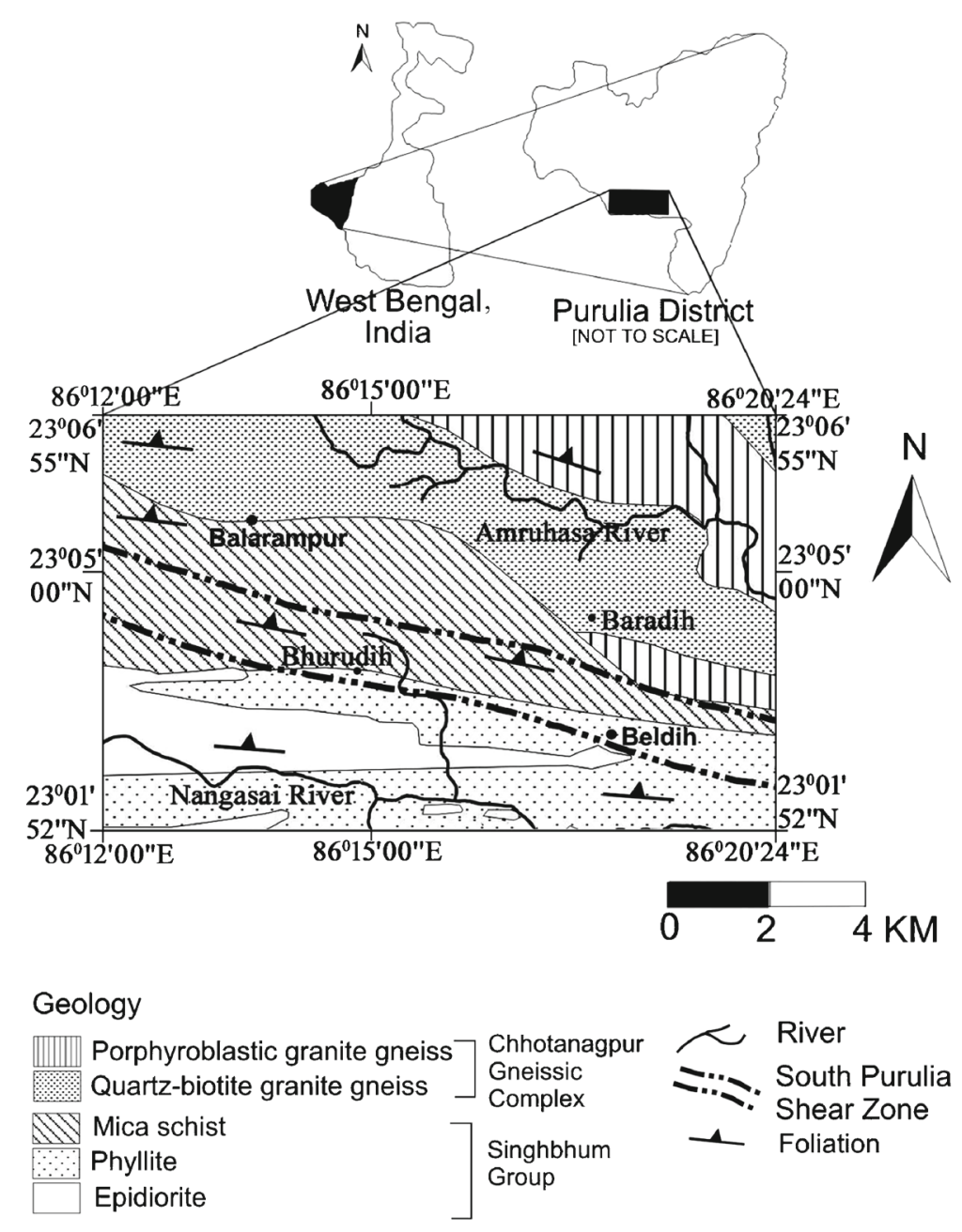

Figure 1. Location map of the study area in and around Balarampur town, Purulia district, West Bengal, India showing geological features.

brought CGGC to the south over IOG (Katti et al. 2010). The structural elements are dominantly shear-joints and fractures in the granitic rocks, pegmatites, quartz veins and metasediments. These shear joints, fractures and faults, in general, strike $\mathrm{E}-\mathrm{W}$ with $60^{\circ} \mathrm{N}$ to near-vertical dips (Geological quadrangle map 73I 1948).

\section{Methods}

Acharya et al. (2012) and Acharya and Mallik (2012) have developed the hydrostructural domain model for the Balarampur region of Purulia district based on interpretations of fracture measurements and lithostructural elements. Three different 'domains' were defined as: (a) region occurring north of SPSZ (D1), (b) the region within the SPSZ (D2) and (c) the region south of the SPSZ (D3). Fracture frequency and aperture data from the bedrock exposures of Precambrian metamorphics and depth to water table in pre- and postmonsoon periods from the existing wells were collected during field studies, which were followed by detailed laboratory analyses for determination of their hydrological significance using softwarebased hydrostructural domain approach. The fracture frequency and aperture analysis for different domains have been categorized as:

- hydrostructural domain-based modal value analysis which involves comparison of modal values of each fracture parameter for different domains,

- hydrostructural domain-based coefficient of variance $(C \nu)$ analysis which involves comparison of fracture families of each domain,

- filtered hydrolithostructural domain-based analysis for lithologies of each hydrostructural domain.

\subsection{Analyses of fracture frequency and aperture}

Statistical analyses of fracture frequency and fracture aperture were performed for three hydrostructural domains D1, D2 and D3 to calculate the coefficient of variance $(C \nu)$ and dominant (modal) 
value for each fracture parameter related to each corresponding domain using Statistica software (StatSoft Inc 1995). Spatial cluster analysis of fracture frequency and fracture aperture were performed by determining the coefficient of variance $(C \nu)$, the ratio of the standard deviation $(\sigma)$ to the mean $(\mu)$ of the respective parameter in each domain using the method of Gillespie et al. (1993, 2001). In statistics, the coefficient of variance $(C \nu)$, measured as $\sigma / \mu$, is a normalized measure of dispersion of a probability distribution and a measure of the dispersion of data points in a data series around the mean. $C \nu$ is useful for comparing the degree of variation of one data series with the other, even if the means are drastically different from each other. The higher the $C \nu$, the greater is the dispersion of the variable, and the variable with the smaller $C \nu$ is less dispersed than the variable with the larger $C \nu$. If fracture properties, for example, frequency and aperture values, are dispersed in a domain, the $C \nu$ will be nearly as high as 1 or even higher, while $C \nu$ will be much less for nearly uniform distribution of fracture parameter values spread throughout the domain, indicating a central tendency of data distribution around the mean. $C \nu$ and modal values of fracture frequencies and apertures for different rock types of the domains are also calculated, using the same procedure to study the variation and the population dispersal pattern of fracture properties within the same and varying lithology.

In this study, an alternative approach is considered. Rather than creating individual small cubes and generating discrete fracture networks within them, outcrop measurements of fracture frequency and aperture distribution at each site are taken, and then upscaled and interpolated to the scale of the study area following 'point kriging method' of geostatistical gridding and estimating the values at the points of grid nodes (Abramowitz and Stegun 1972; Golden Software Inc 2010). Altogether, a total set of 334 fracture-frequency and 334 fracture-aperture data were measured in the study area during the field season of 2011-2012. Based on these collected data, contour maps on continuous fracture frequency and aperture were prepared; their pattern of distribution in the three hydrostructural domains and corresponding lithological units were studied next through visual interpretation and computer-based approach using 'Surfer' software (Golden Software Inc 2010).

\subsection{Hydrological studies}

Detailed hydrological data were collected during the pre-monsoon and post-monsoon seasons of 2012 from 232 inventoried dug wells. The sampling sources were uniformly distributed in all the hydrolithostructural domains under study. The water table contour maps, based on depth-to-water (DTW) level data measured in ' $\mathrm{m}$ bgl' (below ground level), were prepared using the Surfer software (Abramowitz and Stegun 1972). The water table maps along with groundwater flow lines provide essential qualitative clues on the hydrogeological set-up of an area in terms of permeability, flow pattern, hydraulic gradient, and delineation of recharge-discharge regions. With these maps, the inter- and intra-spatial distribution and variability of hydraulic properties corresponding to each hydrolithostructural domain were thus interpreted and compared with the estimates derived from fracture studies.

\section{Results}

The results obtained from statistical analyses of fracture properties based on (1) hydrostructural domain-based modal value analysis, (2) hydrostructural domain-based coefficient of variance $(C \nu)$ analysis, and (3) filtered, hydrolithostructural domain-based fracture analysis show significant and interesting variations of modal and $C \nu$ values of both fracture frequencies (figure 2) and apertures (figure 3 ), as tabulated in table 1 .

\subsection{Hydrostructural domain-based modal value analysis}

Statistical analyses of fracture frequencies (figure 2a, b and c) and apertures (figure 3a, b and c) yield marked differences of representative modal values among the corresponding hydrostructural domains (D1, D2 and D3) in the study area (table 1). Modal fracture frequency is minimum $(3 / \mathrm{m})$ in the northern part of the SPSZ (D1) (figure 2a), maximum $(15 / \mathrm{m})$ in SPSZ (D2) (figure $2 \mathrm{~b}$ ) and intermediate $(10 / \mathrm{m})$ in the southern part of the SPSZ (D3) (figure 2c), clearly indicating highest fracture frequency in the SPSZ (D2). While D1 exhibits maximum fracture aperture $(2 \mathrm{~mm})$ (figure 3a) followed by D3 $(1.5 \mathrm{~mm})$ (figure 3c). D2 shows minimum aperture of 0.5 $\mathrm{mm}$ (figure $3 \mathrm{~b}$ ).

\subsection{Hydrostructural domain-based coefficient of variance $(C \nu)$ analysis}

Statistical analyses of hydrostructural domainbased $C \nu$ values in the study area yield significant distribution of both frequency and aperture in different hydrostructural domains (table 1$). C \nu$ value of fracture frequency is maximum (0.94) in D1 which is close to 1 indicating inconsistency in the 


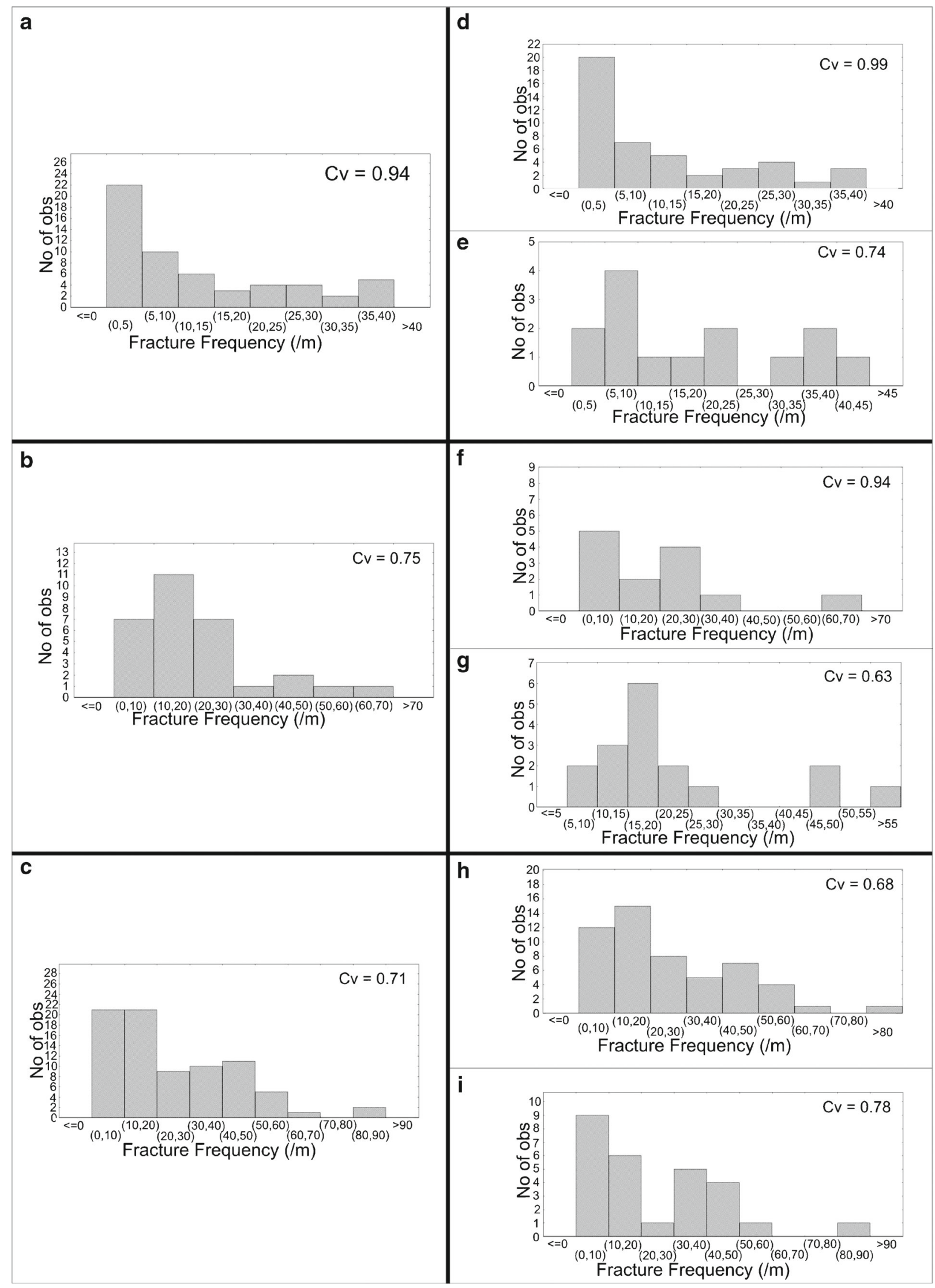

Figure 2. Frequency distribution diagrams of fracture frequency data for hydrostructural domains: (a) north of SPSZ (D1), (b) SPSZ (D2), (c) south of SPSZ (D3) and hydrolithostructural domains, (d) granite gneisses, (e) mica schist in D1, (f) mica schist, (g) phyllite in D2, (h) phyllite and (i) epidiorite in D3. The differences in modal values in the data distribution diagrams and $C \nu$ of fracture frequencies are noticeable. $C \nu=$ coefficient of variance. 


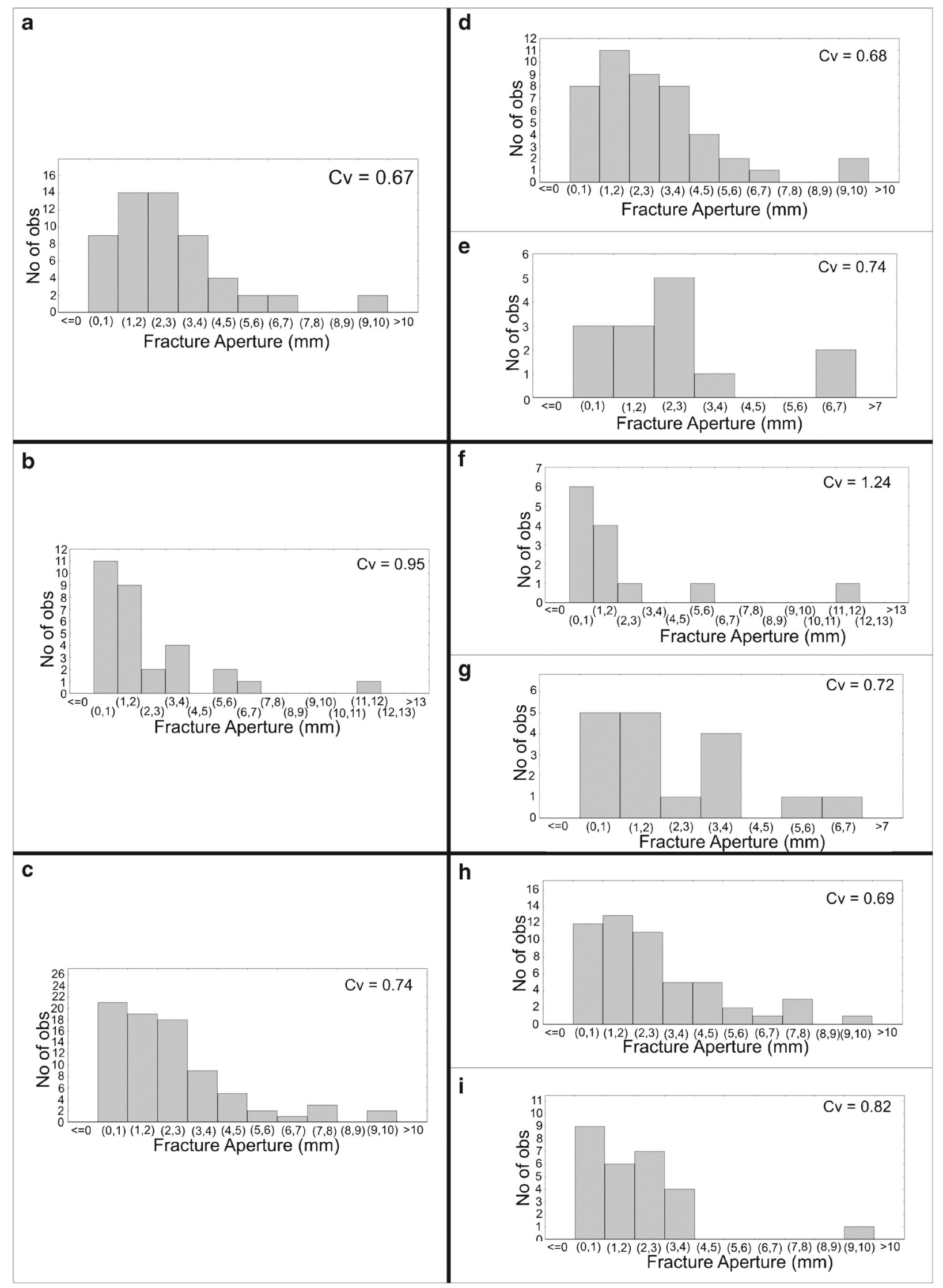

Figure 3. Frequency distribution diagrams of fracture aperture data for hydrostructural domains: (a) north of SPSZ (D1), (b) SPSZ (D2), (c) south of SPSZ (D3) and hydrolithostructural domains: (d) granite gneisses, (e) mica schist in D1, (f) mica schist, (g) phyllite in D2, (h) phyllite and (i) epidiorite in D3. The differences in modal values in the data distribution diagrams and $C \nu$ of fracture apertures are noticeable. $C \nu=$ coefficient of variance. 
Table 1. Fracture statistics of the studied hydrostructural and hydrolithostructural domains showing fracture frequency and aperture distributions.

\begin{tabular}{|c|c|c|c|c|c|c|c|c|c|}
\hline \multirow[b]{2}{*}{$\begin{array}{l}\text { Hydrostructural } \\
\text { domain }\end{array}$} & \multicolumn{2}{|c|}{$\begin{array}{l}\text { Fracture } \\
\text { frequency }\end{array}$} & \multicolumn{2}{|c|}{$\begin{array}{l}\text { Fracture } \\
\text { aperture }\end{array}$} & \multirow[b]{2}{*}{$\begin{array}{l}\text { Hydrolitho- } \\
\text { structural domain }\end{array}$} & \multicolumn{2}{|c|}{$\begin{array}{l}\text { Fracture } \\
\text { frequency }\end{array}$} & \multicolumn{2}{|c|}{$\begin{array}{l}\text { Fracture } \\
\text { aperture }\end{array}$} \\
\hline & $\begin{array}{c}\text { Modal } \\
\text { value }(/ \mathrm{m})\end{array}$ & $C \nu$ & $\begin{array}{c}\text { Modal } \\
\text { value }(\mathrm{mm})\end{array}$ & $C \nu$ & & $\begin{array}{c}\text { Modal } \\
\text { value }(/ \mathrm{m})\end{array}$ & $C \nu$ & $\begin{array}{c}\text { Modal } \\
\text { value }(\mathrm{mm})\end{array}$ & $C \nu$ \\
\hline \multirow[t]{2}{*}{ D1 } & 3 & 0.94 & 2 & 0.67 & Granite gneisses & 3 & 0.99 & 2 & 0.68 \\
\hline & & & & & Mica schist & 7 & 0.74 & 2.5 & 0.74 \\
\hline \multirow[t]{2}{*}{ D2 } & 15 & 0.75 & 0.5 & 0.95 & Mica schist & 5 & 0.94 & 0.6 & 1.24 \\
\hline & & & & & Phyllite & 18 & 0.63 & 1 & 0.72 \\
\hline \multirow[t]{2}{*}{ D3 } & 10 & 0.71 & 1.5 & 0.74 & Phyllite & 15 & 0.68 & 1.5 & 0.69 \\
\hline & & & & & Epidiorite & 5 & 0.78 & 0.5 & 0.82 \\
\hline
\end{tabular}

Note: $/ \mathrm{m}=$ number per meter, $C \nu=$ coefficient of variance.

distribution of low fracture frequencies throughout the D1 domain. The southern part of the SPSZ (D3) shows minimum $C \nu$ (0.71) of frequency indicating most consistently distributed moderate fracture frequencies within D3 domain. SPSZ (D2) exhibits intermediate $C \nu(0.75)$ revealing intermediate regularity in distribution of high frequency values. $C \nu$ analysis of fracture apertures clearly reveals least dispersal of high aperture data in D1 $(C \nu=0.67)$, while maximum dispersal and inconsistency of low apertures exists in D2 $(C \nu=0.95)$. D3 indicates moderate consistency in distribution of moderate apertures with $C \nu$ of 0.74 .

\subsection{Filtered, hydrolithostructural domain-based analysis}

Statistical analysis of the fracture frequencies and apertures indicates marked differences of modal values and $C \nu \mathrm{s}$ even in the same hydrostructural domain for different lithological subdomains. Table 1 exhibits the advantage of the filtered, hydrolithostructural domain-based analysis over the hydrostructural domain based technique.

In D1 hydrostructural domain, there are two litho-domains - granite gneisses and mica schist. Modal fracture frequency of granite gneisses $(3 / \mathrm{m})$ (figure 2d) in D1, which is comparable to the overall D1 value $(3 / \mathrm{m})$, is less than that of mica schist $(7 / \mathrm{m})$ (figure $2 \mathrm{e}$ ). Moreover, lower $C \nu$ of frequencies in mica schist (0.74) than granite gneisses (0.99) indicates more regular distribution of higher fracture frequency values in mica schist than granite gneisses in D1 and overall D1 domain $(C \nu=0.94)$ too (table 1$)$. Thus the filtered, hydrolithostructural domain-based analysis yields more isotropic distribution of higher frequency in mica schist hydrolithostructural domain in D1 than the anisotropically distributed lower frequency in overall D1 hydrostructural domain.
In SPSZ (D2), phyllite and mica schist are two lithological domains. In D2 domain mica schist shows lower modal frequency $(5 / \mathrm{m})$ with higher degree of data dispersal $(C \nu=0.94)$ (figure 2f) than overall D2 (modal value $=15 / \mathrm{m}$, $C \nu=0.75)$ assigning mica schist less significant in the D2 hydrostructural domain (table 1). Phyllite hydrolithostructural domain in D2 hydrostructural domain shows combination of maximum modal fracture frequency $(18 / \mathrm{m})$ and minimum $C \nu$ (0.63) among all hydrolithostructural domains demonstrating maximum consistency in distribution of highest frequency values throughout this hydrolithostructural domain within the shear zone region (figure $2 \mathrm{~g}$ ), which is also much higher than the overall values of the host D2 hydrostructural domain $($ modal value $=15 / \mathrm{m}, C \nu=0.75)($ table 1$)$.

In D3, the lithological domain, phyllite shows higher modal frequency $(15 / \mathrm{m})$ with more regular distribution of data $(C \nu=0.68)$ (figure $2 \mathrm{~h}$ ) than epidiorite litho-domain exhibiting lower modal frequency $(5 / \mathrm{m})$ with larger dispersal of data $(C \nu=0.78)$ (figure 2i). Again, hydrolithostructural domain phyllite in D3 is also demonstrating more isotropic distribution of higher frequency values than that of the overall D3 hydrostructural domain (modal value $=10 / \mathrm{m}, C \nu=0.71$ ) (table 1).

In D1, the modal value of fracture aperture in granite gneisses $(2 \mathrm{~mm})$ (figure $3 \mathrm{~d}$ ) is lower than mica schist $(2.5 \mathrm{~mm}$ ) (figure $3 \mathrm{e}$ ) with more regular distribution of this value in granite gneisses $(C \nu=$ $0.68)$ than mica schist $(C \nu=0.74)$. The aperture in mica schist in D2 is lower (0.6 mm) (figure $3 \mathrm{f}$ ) than that in phyllite $(1 \mathrm{~mm})$ (figure $3 \mathrm{~g}$ ) and also showing higher dispersal $(C \nu=1.24)$ than phyllite $(C \nu=0.72)$. Hence, phyllite hydrolithostructural domain in D2 is more hydraulically significant than mica schist hydrolithostructural domain. Therefore, inconsistency in distribution of aperture values in D2 hydrostructural domain may be subclassified into hydrolithostructural domains to 
yield more isotropically distributed higher aperture values in phyllite in D2 (table 1). In D3, phyllite hydrolithostructural domain shows higher aperture $(1.5 \mathrm{~mm})$ (figure $3 \mathrm{~h}$ ) than hydrolithostructural domain epidiorite (0.5) (figure $3 \mathrm{i}$ ). Moreover, comparison of $C \nu$ values indicates more regular high data distribution in phyllite $(C \nu=$ $0.69)$ than in epidiorite in D3 $(C \nu=0.82)$ and also in overall D3 hydrostructural domain $(C \nu=$ 0.74), assigning phyllite to be more hydraulically significant than epidiorite in D3 hydrostructural domain (table 1).

\subsection{Fracture frequency contour map}

Fracture frequency contour map (figure 4) reveals an overall low fracture frequency value along with some patches of moderate values in D1; this depicts the anisotropic distribution of fracture frequency in D1. The litho-domain mica schist in D1 exhibits slightly higher and more consistent frequency values than the litho-domain granite gneisses. D2 domain shows high fracture frequency values with moderately consistent distribution. Frequency values are sporadic and highly anisotropic with pockets of low and moderately high values in mica schist in D2. Phyllite in D2 is most isotropic in frequency distribution showing very high values. High fracture frequency is more or less isotropically distributed in D3. In D3, phyllite illustrates very high frequency values most isotropically throughout this litho-domain, whereas epidiorite shows overall low frequency with a high value pocket revealing moderately anisotropic frequency distribution pattern in this litho-domain. Thus interpretation of fracture frequency contour map shows clear concordance with the results of domain-based and filtered, litho-domain-based analysis techniques and demonstrates the occurrence of preferentially more isotropically distributed hydrolithostructural domains in the study area.

\subsection{Fracture aperture contour map}

Fracture aperture contour map (figure 5) reveals consistent high D1 values with some stray patches of low value. Maximum aperture is noted at the north-central portion of the gneisses in D1, while mica schist shows high values at the centre and the north-western corner. D2 manifests lowest aperture value with a narrow central zone of moderate apertures in mica schist and phyllite, within which a slightly higher value is observed in central

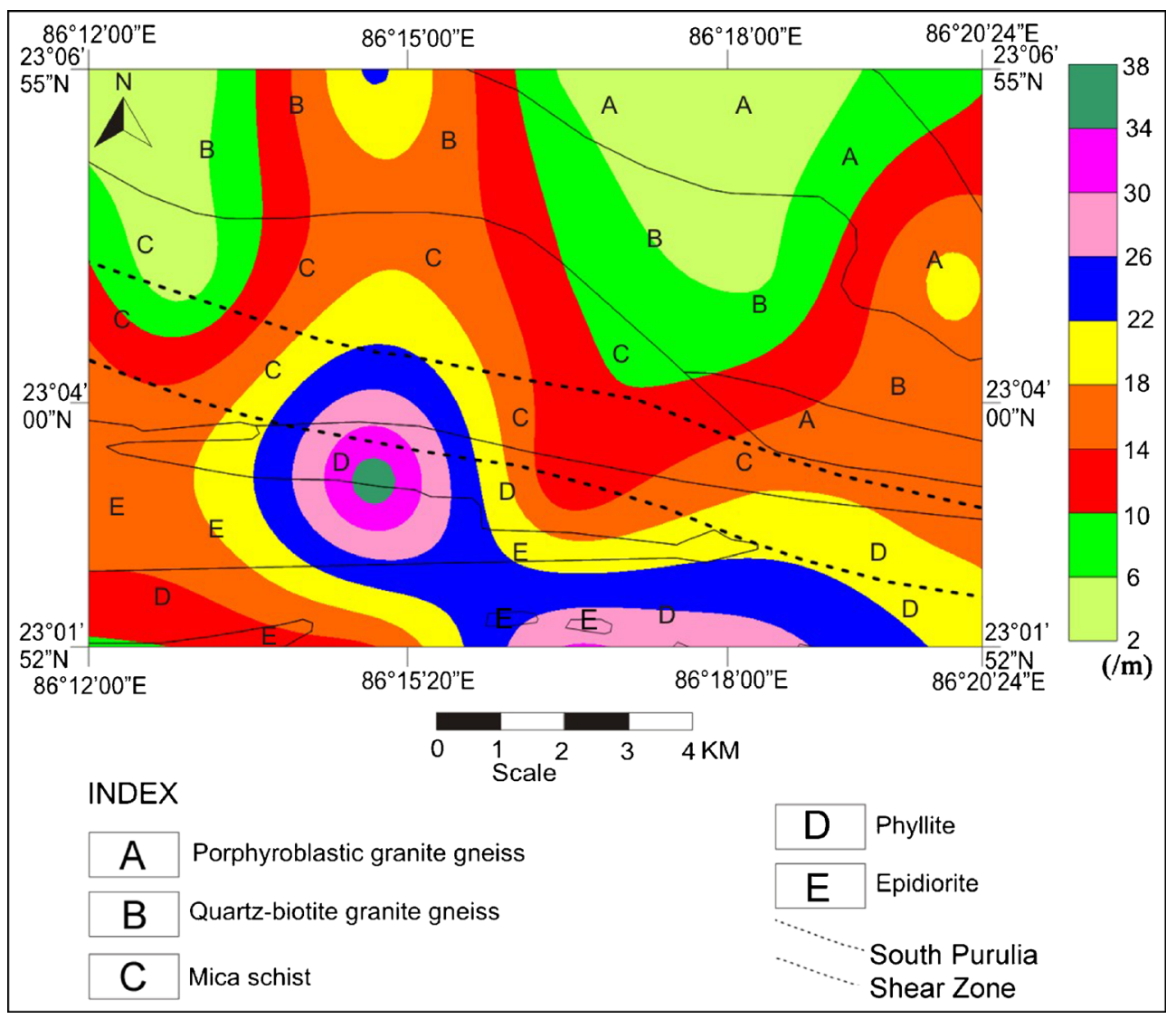

Figure 4. Fracture frequency contour map, in '/m' of the study area showing marked differences for different hydrostructural domains. High values are prominent in the southern to central region indicating hydrolithostructural affinity. 


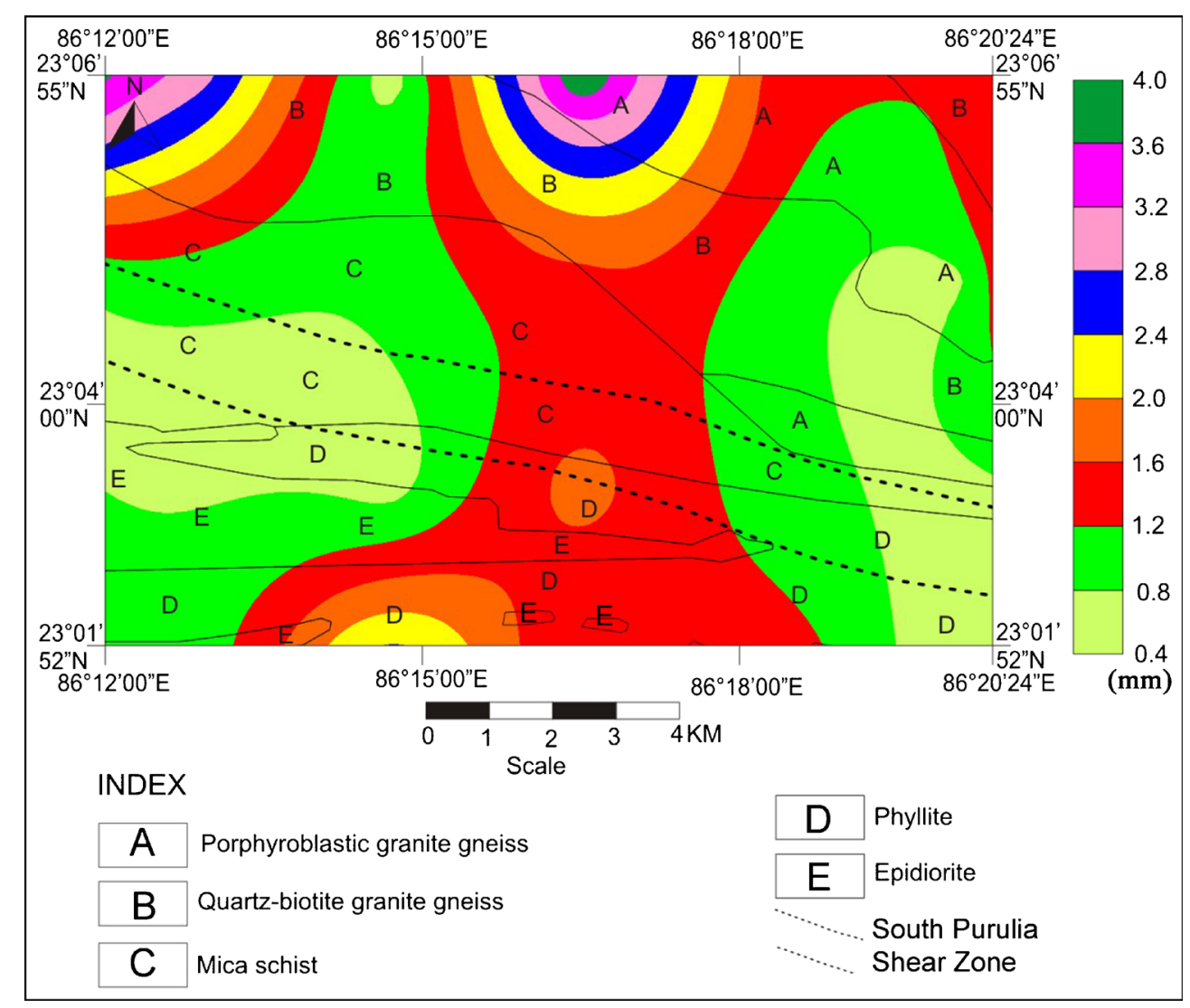

Figure 5. Fracture aperture contour map, in 'mm' of the study area showing marked differences for different hydrostructural domains. High values are prominent in the northern part with a pocket in the southern region indicating hydrolithostructural affinity.

part of phyllite, depicting an inconsistent central zone. Fracture aperture in D3 shows intermediate values between D1 and D2. Epidiorite exhibits an overall low aperture with a small patch of moderate value in the central part, whereas phyllite reveals an overall intermediate to high value almost throughout the D3. The aperture characteristics and distribution pattern in the study area is clearly consistent with the results of domain-based and filtered litho-domain-based analysis and exhibits the smooth isotropic locales when considering the hydrolithostructural domains.

\subsection{Water table contour maps}

In the water table contour maps of pre-monsoon (figure 6) and post-monsoon (figure 7) seasons of 2012 , the ground water contour spacing variation indicates strong variation of hydraulic gradient in the study area. The same could broadly be categorized into five groups namely, $<3 \mathrm{~m} \mathrm{bgl}$, between 3 and $5 \mathrm{~m} \mathrm{bgl}, 5-7 \mathrm{~m} \mathrm{bgl}, 7-9 \mathrm{~m} \mathrm{bgl}$, and between 9 and $10 \mathrm{~m} \mathrm{bgl}$. The depth-to-water table during the pre-monsoon season ranges from 2 to 10 $\mathrm{m} \mathrm{bgl}$, while the same fluctuates between 1.7 and $9.89 \mathrm{~m}$ bgl during the post-monsoon months. The pre-monsoon depth-to-water table contour map (figure 6) reveals shallow (within $5 \mathrm{~m} \mathrm{bgl}$ ) water table condition in central and southern parts of the study area. The depth-to-water table contour map during the post-monsoon period (figure 7) exhibits shallowest position at the southern part with some similar stray pockets at the northern and central portions. Study of divergence pattern of flow lines at the southern and central parts of the study area during pre- and post-monsoon periods indicate recharge possibilities at these areas. Comparative review of pre- and post-monsoon contour data have also shed significant light on storativity status of the aquifers, as direct response to recharge-discharge characteristics. Good correlation could be established between well-jointed rock strata and their hydrological potentialities. For example, high rise in water table noted in post-monsoon season on the southern part of the study area and moderately high water table values of north-central region could be attributed to existence of joint systems. Higher permeability was noted in the hydrolithostructural domain of phyllites outside SPSZ (D3) and also within phyllite patches of SPSZ (D2), while mica schist outside SPSZ (D1) exhibits broad pockets of moderately 


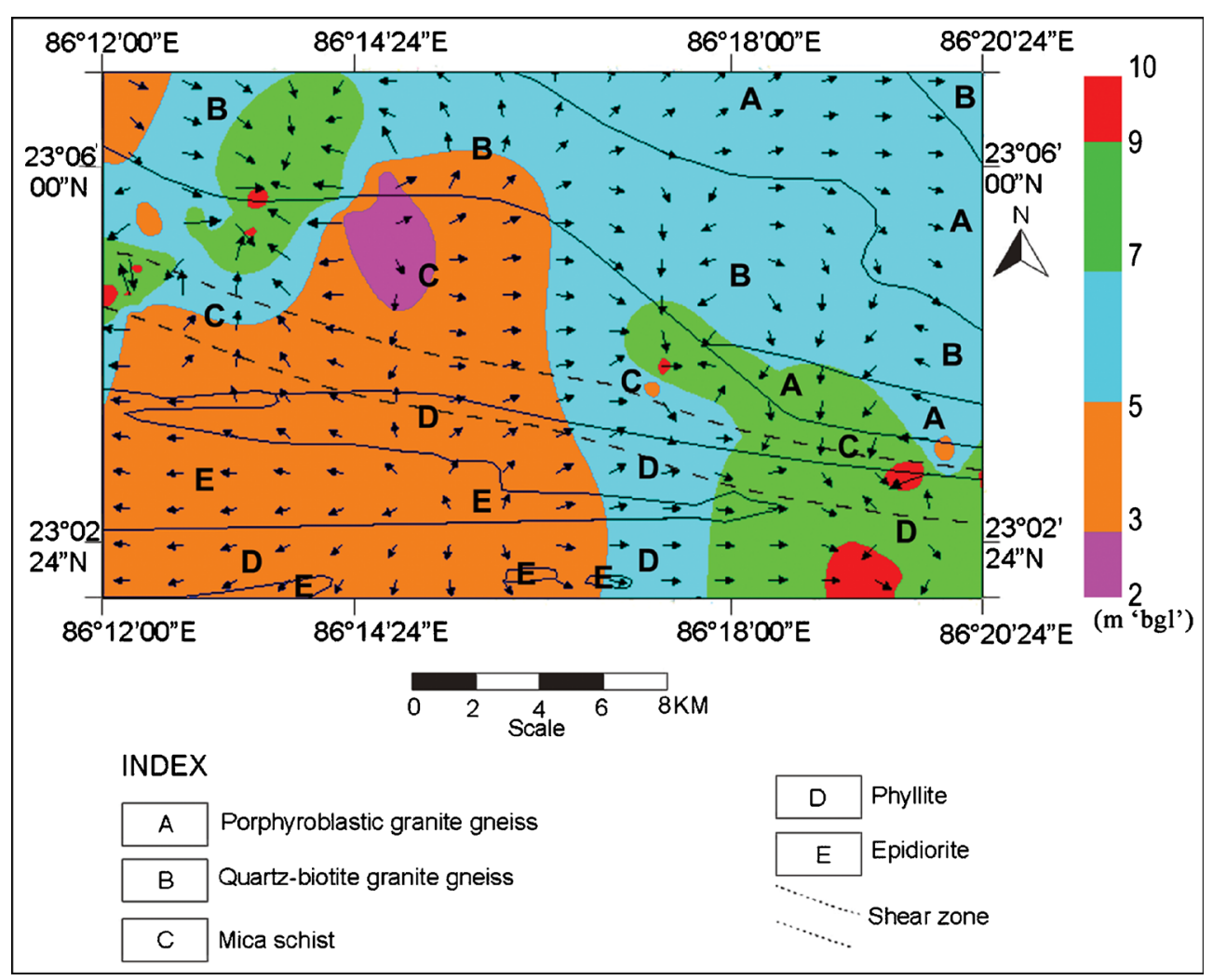

Figure 6. Water level contour map, in ' $\mathrm{m}$ bgl' and groundwater flow lines of the study area at pre-monsoon time in session 2012 showing hydraulically permeable locales and recharge areas revealing its concurrence with specific hydrolithostructural domains.

high permeable zones followed by small pockets in the gneisses in D1.

\section{Discussion}

The heterogeneity of fractured aquifers is interpreted with reference to the bulk hydraulic properties of the hydrolithostructural domains. Detailed analysis of fracture frequency and aperture for different domains utilizing hydrostructural domain approach includes hydrostructural domain-based analysis and filtered, hydrolithostructural domainbased analysis for estimating the hydrological behaviour of the Precambrian metamorphic terrain. The hydrostructural domains are found to be statistically different in terms of the magnitude and spatial distribution pattern of hydraulically significant fracture characteristics, i.e., frequency and aperture of fractures. Hydrostructural domain-based analysis clearly demonstrates more anisotropic and irregular distribution of the fracture frequency data than the filtered, hydrolithostructural domain-based analysis. Filtered, hydrolithostructural domain-based analysis yields higher modal value with more isotropic distribution of frequency when compared to the corresponding hydrostructural domain-based analysis in each domain (D1, D2 and D3) indicating smoothening from the anisotropic to more isotropic nature of distribution of higher frequency values in filtered, hydrolithostructural domain-based analysis which is also sustained in the fracture frequency contour map. Thus filtered, hydrolithostructural domain-based analysis has inherent advantages over the hydrostructural domain-based analysis of fracture frequency characteristics. Filtered, hydrolithostructural domain-based analysis and the contour map of fracture frequency indicate that phyllite within the SPSZ (D2) is characterized by spatially isotropic distribution of highest frequency among all lithological types present in the study area. Phyllite occurring south of SPSZ (D3) also exhibits isotropic distribution of high fracture frequency. Phyllite within the shear zone (D2) and outside the shear zone (D3) show overall fracture frequency of $18 / \mathrm{m}$ and $15 / \mathrm{m}$, respectively which are high enough for being hydraulically significant fractures (Boutt et al. 2010; Acharya et al. 2012). Lower $C \nu$ in shear zone than outside for phyllite depicts more isotropic distribution of higher values in the domain of shear zone for same litho-domain type signifying positive correlation between occurrence of isotropic high fracture frequency and shear zone for the same litho-domain phyllite, whereas mica schist depicts the reverse relationship 


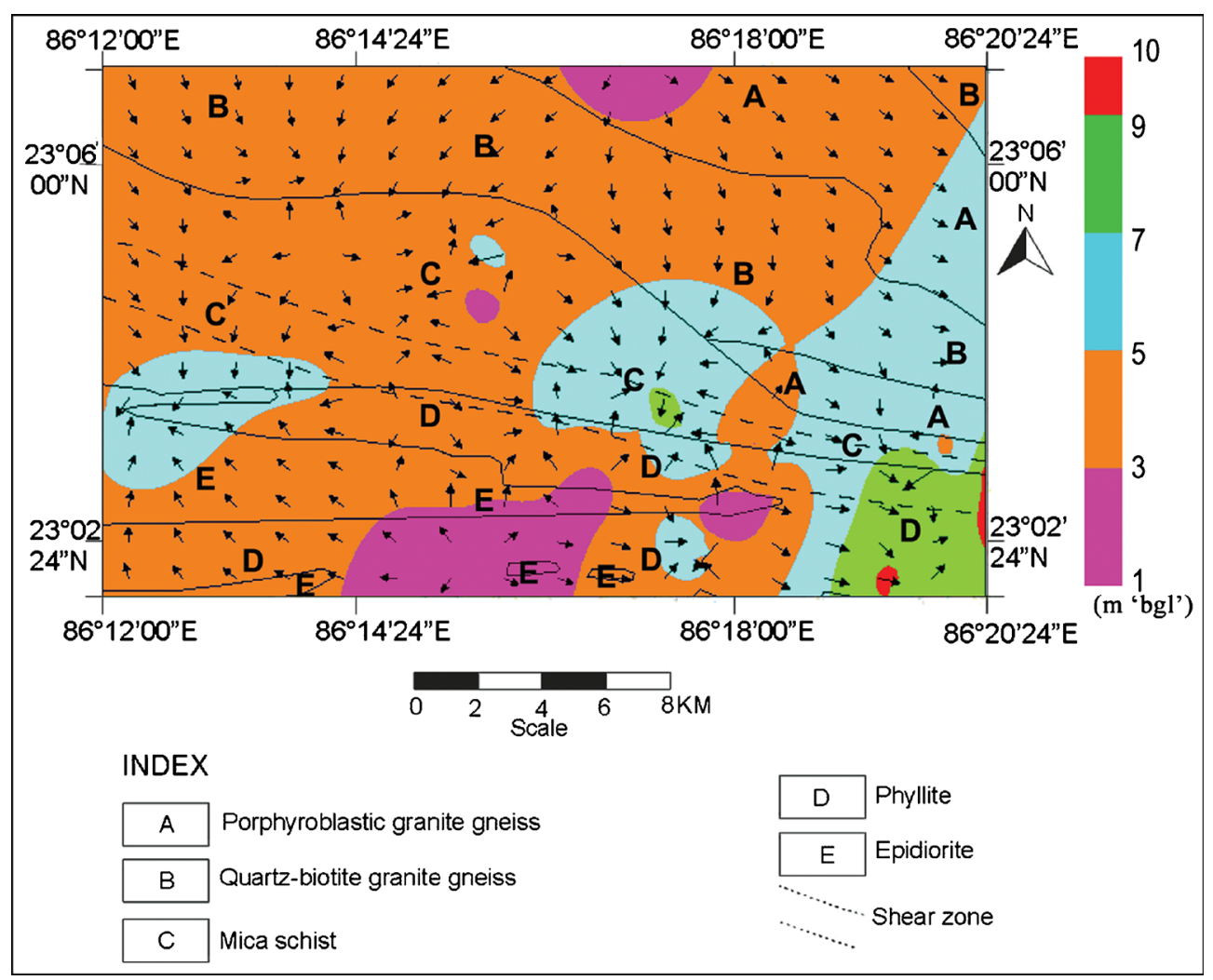

Figure 7. Water level contour map, in ' $\mathrm{m}$ bgl' and groundwater flow lines of the study area at post-monsoon time in session 2012 showing hydraulically permeable locales and recharge areas revealing its concurrence with specific hydrolithostructural domains.

reflecting more plastic characteristics of mica schist under intense shearing (Murat 1988).

Partitioning of domain-based analysis of fracture aperture data into lithological variation through filtered, hydrolithostructural domain-based analysis yields well partitioned specific hydrolithostructural domains with regularly distributed high aperture. Filtered, hydrolithostructural domain-based analysis of fracture aperture indicates that mica schist and granite gneisses litho-domains within the D1 hydrostructural domain is characterized by spatially moderately scattered distribution of highest aperture among all lithological types present in the study area followed by the hydrolithostructural domain phyllite in D3 and D2, respectively which are also concordant with the fracture aperture contour map. Lower $C \nu$ in areas outside the shear zone (D3) than within the shear zone (D2) for phyllite depicts more isotropic distribution of higher aperture values in the domain outside the shear zone for same litho-domain type phyllite. These specific aperture characteristics are also similarly valid for litho-domain mica schist outside and within shear zone signifying inverse correlation between occurrence of shear zone and consistently isotropic high fracture aperture for the same litho-domain, and may be attributed to the high stress field under intense shearing within shear zone. Several workers demonstrated that fracture apertures decrease at greater rates at higher stress magnitudes (Bandis et al. 1983; Brown and Scholz 1986; Hillis 1987) and also because of the combined fact that weathering products due to intense shearing of metapelitic rocks include clay minerals that tend to fill the fractures and thus decrease the overall effective fracture aperture (Cook 2003).

The combined interpretation of fracture frequency and aperture characteristics from filtered, hydrolithostructural domain-based and contour map analysis identify the phyllites that lie outside or within the shear zone as two hydraulically significant hydrolithostructural domains in the study area. Mica schist and granite gneisses, both outside shear zone, represent two other important hydrolithostructural domains in specific pockets in concurrence with high fracture aperture zone, though mica schist represents larger significant region than granite gneisses. This is also supported by Singhal and Gupta (1999) demonstrating schists as more productive with more conspicuous foliation than gneisses. Interestingly, the decreasing sequence of hydraulically significant litho-domains from phyllite to gneisses through mica schist is also in concordance with the increasing degree of metamorphism indicating its control to determine the strength of the rock against fracturing, lending 
concurrence to the fact that high grade rocks show little fracturing while low grade rocks show intense fracturing (Alemayehu 2006). As lithology affects mechanical properties and controls the degree of jointing from post-metamorphic brittle deformation (Williams 2003), the utility and advantage of filtered, hydrolithostructural domain-based analysis is further established.

Regions of high recharge potentiality and better permeable areas deduced from water level contour maps show strong correlation with the results derived from filtered hydrolithostructural domainbased analyses of fracture frequency and aperture size. The similarity in hydraulic properties derived from direct field measurement and from modelling serves to validate the hydrolithostructural domain approach to estimate hydraulic properties. As a result, the method used in the present research may have applications in other areas where groundwater resources in fractured rock aquifers are of interest.

\section{Conclusion}

The present paper provides a ground exemplar of software-based approach for analyses of fracture data through hydrostructural modelling. Measurements of these data such as fracture frequency and aperture were undertaken from outcrops of hard country rocks. The findings have led to generation of hydraulically significant hydrolithostructural domains similar to those obtained from hydrological investigations. Moreover, the hydraulically significant hydrolithostructural domain thus arrived at has higher spatial resolution than that simply deciphered from hydrostructural domain model or through discrete pump tests.

The results of this study demonstrate that hydrolithostructural domain approach can be successfully utilized to characterize potential groundwater recharge areas and permeable zones on a regional scale. Elevated groundwater recharge and permeability is detected in phyllite and mica schist without any shearing effect followed by granite gneisses outside the shear zone, whereas only phyllite can show some hydraulically significant locales within the shear zone. At the existing inventory well sites, spatial distribution of hydrological characteristics was noted. Overall, the above model derived potential hydraulically significant hydrolithostructural domains that showed consistence with the hydrological observations from the inventory wells.

\section{Acknowledgements}

The authors express their sincere gratitude to Dr S K Mukhopadhyay, Principal of Hooghly Mohsin
College, West Bengal, India for his constant support and inspiration during the course of this research work. Authors are also thankful for the valuable comments of $\mathrm{Dr}$ A K Chaubey, Editor and two anonymous reviewers in improving the manuscript further.

\section{References}

Abbey D G and Allen D M 2000 Fracture zones, aquifer testing, and scale effects: Considerations in fractured bedrock aquifers of southwestern British Columbia; Proceedings of the 53rd Canadian Geotechnical Conference, Montreal.

Abramowitz M and Stegun I 1972 Handbook of Mathematical Functions; Dover, New York.

Acharya T and Mallik S B 2012 Analysis of lineament swarms in a Precambrian metamorphic rocks in India; J. Earth. Syst. Sci. 121(2) 453-462, doi: 10.1007/s12040012-0164-z.

Acharya T, Nag S K and Mallik S B 2012 Hydrologic significance of fracture correlated lineaments in Precambrian rocks in Purulia District, West Bengal; J. Geol. Soc. India 80(5) 723-730, doi: 10.1007/s12594-012-0198-5.

Alemayehu T 2006 Groundwater occurrence in Ethiopia; Addis Ababa University, Ethiopia, pp. 26-27.

Auradou H, Drazer G, Hulin J P and Koplik J 2005 Permeability anisotropy induced by the shear displacement of rough fracture walls; Water Resour. Res. 41(W09423), doi: 10.1029/2005WR003938.

Baidya T K 1992 Apatite-magnetite deposit in the Chhotanagpur Gneissic Complex, Panrkidih area, Purulia District, West Bengal; Indian J. Geol. 64(1) 88-95.

Bandis S, Lumsden A and Barton N 1983 Fundamentals of rock joint deformation; Int. J. Rock Mech. Min. Sci. Geomech. (Abstr.) 20(6) 249-268.

Bertels S P, DiCarlo D A and Blunt M J 2001 Measurement of aperture distribution, capillary pressure, relative permeability, and in situ saturation in a rock fracture using computed tomography scanning; Water Resour. Res. 37(3) 649-662.

Bhattacharya D S 1989 Ductile shear zone in Purulia, WB, India; J. Geol. 61 172-178.

Boutt D F, Diggins P and Mabee S 2010 A field study (Massachusetts, USA) of the factors controlling the depth of groundwater flow systems in crystalline fractured-rock terrain; Hydrogeol. J. 18 1839-1854.

Braathen A 1999 Kinematics of post-Caledonian polyphase brittle faulting in the Sunnfjord region, western Norway; Tectonophys. 302 99-121.

Brown S and Scholz C 1986 Closure of rock joints; J. Geophys. Res. Solid Earth 91(B5) 4939-4948.

Brown S R 1987 Fluid flow through rock joints: The effect of surface roughness; J. Geophys. Res. 92 1337-1347.

Cook P G 2003 A guide to regional groundwater flow in fractured rock aquifers; CSIRO Land and Water, Australia.

Dasgupta S 2004 Modelling ancient orogens - an example from north Singhbhum Mobile Belt; Geol. Surv. India (Spec. Publ.) 84 33-42.

Geological Quadrangle Map 73I 1948 Geological Survey of India, Calcutta.

Gillespie P A, Howard C, Walsh L L and Watterson L 1993 Measurement and characterisation of spatial distributions of fractures; Tectonophys. 226 113-141.

Gillespie P A, Walsh J J, Watterson J, Bonson C G and Manzocchi T 2001 Scaling relationships of joint and vein 
arrays from the Burren Co. Clare, Ireland; J. Struct. Geol. 23 183-201.

Golden Software Inc 2010 Surfer Version 9.9.785, Surface Mapping System, 809 14th Street, Golden, Colorado, 80401-1866.

Gupta A and Basu A 2000 North Singhbhum Proterozoic mobile belt, Eastern India - A review; Geol. Surv. India (Spec. Publ.) 55 195-226.

Henriksen H and Braathen A 2006 Effects of fracturelineaments and in situ rock stresses on groundwater flow in hard rocks: A case study from Sunnfjord, Western Norway; Hydrogeol. J. 14 444-461.

Hillis R 1987 The influence of fracture stiffness and the in situ stress field on the closure of natural fractures; Petrol. Geosci. 4(1) 57-65.

Katti V J, Sen J and Bhatt A K 2010 Uranium potentiality of South Purulia Shear Zone in Eastern Indian Shield; Technical Meeting on Low Grade Uranium Ore, International Atomic Energy Agency (IAEA), Vienna, Austria.

Lapcevic P A, Novakowski K S and Sudicky E A 1999 Groundwater flow and solute transport in fractured media; In: Handbook of Groundwater Engineering (ed.) Raton B A, CRC Press, LLC.

Mabee S B and Hardcastle K C 1997 Analyzing outcropscale fracture features to supplement investigations of bedrock aquifers; Hydrogeol. J. 5 21-36.

Mabee S B and Kopera J P 2007 Fracture characterization mapping for regional geologic studies: The hydrostructural domain approach, Ayer Quadrangle, Massachusetts; US EPA/NGWA Fractured Rock Conference: State of the Science and Measuring Success in Remediation, pp. 169186.

Mackie D M 2002 An integrated structural and hydrogeologic investigation of the fracture system in the Upper Cretaceous Nanaimo Group, southern Gulf Islands, British Columbia [M.Sc. thesis]: Burnaby, Simon Fraser University, 358p.

Mallik S B, Bhattacharya D C and Nag S K 1983 Behaviour of fractures in hard rocks - a study by surface geology and radial VES method; Geoexploration 21 181-189.

Manda A K, Mabee S B and Boutt D F 2007 Discrete fracture network modeling of hydrostructural domains: An example from Eastern Massachusetts; US EPA/NGWA Fractured Rock Conference: State of the Science and Measuring Success in Remediation, pp. 480-488.

Martin M W and Tannant D D 2004 A technique for identifying structural domain boundaries at the Ekati Diamond Mine; Eng. Geol. 74 247-264.
Matsuki K, Chida Y, Sakaguchi K and Glover P W J 2006 Size effect on aperture and permeability of a fracture as estimated in large synthetic fractures; Int. J. Rock Mech. Min. 43 726-755.

Murat A V C I 1988 Airphoto interpretation as an aid to litho-structural mapping in tropical terrain - The New Federal Capital City site, Abuja, Nigeria; Miner. Res. Expl. Bull. 108 65-75.

Nag S K 1999 Hydrogeomorphic and fracture studies for groundwater investigation in and around Balarampur, Purulia District, West Bengal; ERIM Int. Con., Vancouver, Canada, VI, pp. 507-514.

Oda M 1985 Permeability tensor for discontinuous rock masses; Geotechnique 35 483-495.

Ohlmacher G C 1999 Structural domains and their potential impact on recharge to Intermontane-basin aquifers; Environ. Eng. Geosci. 5(1) 61-71.

Pan J B, Lee C C, Lee C H, Yeh H F and Lin H I 2010 Application of fracture network model with crack permeability tensor on flow and transport in fractured rock; Eng. Geol. $116166-177$.

Singhal B B S and Gupta R P 1999 Applied hydrogeology of fractured rocks; Kluwer Academic, Dordrecht.

StatSoft Inc. 1995 STATISTICA for Windows [Computer program manual], 2325 East 13th Street, Tulsa, OK 74104.

Surrette M J and Allen D M 2008 Quantifying heterogeneityin variably fractured sedimentary rock using a hydrostructural domain; Geol. Soc. Am. Bull. 120(1-2) 225-237.

Surrette M, Allen D M and Journeay M 2008 Regional evaluation of hydraulic properties in variably fractured rock using a hydrostructural domain approach; Hydrogeol. J. 6 11-30.

Tsang Y W and Witherspoon P A 1981 Hydromechanical behavior of a deformable rock fracture subject to normal stress; J. Geophys. Res. 86 9287-9298.

Wang E Z, Yue Z Q, Tham L G, Tsui Y and Wang H T 2002 A dual fracture model to simulate largescale flow through fractured rocks; Can. Geotech. J. 39 1302-1312.

White B A and Burbey T J 2007 Evidence for structurally controlled recharge in the Blue Ridge Province, Virginia, USA; Hydrogeol. J. 15 929-943.

Williams L J 2003 Influence of foliation fracture systems on water availability in the Lawrenceville, Georgia area; In: Proceedings of the 2003 Georgia Water Resources Conference, Institute of Ecology (ed.) Hatcher K J, The University of Georgia, Athens, Georgia. 